\title{
Hyperimmunoglobulin D Syndrome: Case Report
}

\author{
Hacer ŞEN, ${ }^{1}$ Fatma SILAN, ${ }^{2}$ Emine BİNNETOĞLU, ${ }^{1}$ Fahri GÜNEŞ, ${ }^{1}$ \\ Çisem AKURUT, ${ }^{2}$ Ahmet ULUDAĞ ${ }^{2}$ Öztürk ÖZDEMİR ${ }^{2}$ \\ ${ }^{1}$ Department of Internal Medicine, Çanakkale Onsekiz Mart University, Çanakkale, Turkey \\ ${ }^{2}$ Department of Medical Genetics, Çanakkale Onsekiz Mart University, Çanakkale, Turkey
}

\begin{abstract}
Hyperimmunoglobulin D syndrome is a rare autosomal recessive inherited disease characterized by fever attacks, which may be accompanied by chills, headache, abdominal pain, and cervical lymphadenopathy. Typical hyperimmunoglobulin D syndrome patients start to show symptoms in the first years of life. Diagnosis is based on the presence of symptoms with reduction in the enzyme activity of mevalonate kinase or by detecting the mutation in the mevalonate kinase gene that causes the disease. In this article, we present a 21-year-old female patient who started having fever attacks in early childhood and was diagnosed with familial Mediterranean fever; however, in spite of treatment, whose complaints did not resolve. The genetic analysis, which detected homozygote mevalonate kinase gene mutation and resulted in the hyperimmunoglobulin $D$ syndrome diagnosis, is presented with an accompanying discussion of the literature.

Keywords: Hereditary autoinflammatory disease; hyperimmunoglobulin D syndrome; mevalonate kinase mutation.
\end{abstract}

Hyperimmunoglobulin D syndrome (HIDS) is a rare hereditary autoinflammatory disease characterized by attacks lasting 3-7 days recurring every 4-8 weeks. The most important finding is recurring fever, which may be accompanied by headache, myalgia, arthralgia, abdominal pain, vomiting, diarrhea, cervical lymphadenopathy, aphthous ulcers, and skin rash. ${ }^{1}$ It develops as a result of mutations of the gene coding for the enzyme mevalonate kinase (MVK). ${ }^{2}$ The gene is located on the long arm of the $12^{\text {th }}$ chromosome (12q24). ${ }^{3}$ HIDS diagnosis is based on reduction in MVK enzyme activity or by detecting the mutations of the MVK gene causing the disease.

During attacks, acute phase response is monitored in patients. Laboratory investigations show leukocytosis, increased erythrocyte sedimentation rate, and increased levels of both $\mathrm{C}$ reactive protein and serum amyloid A. ${ }^{4}$ Increased polyclonal serum immunoglobulin (Ig)D is accepted as a distinguishing feature of the disease; however, it is not diagnostic. Increased serum IgA levels are found in $80 \%$ of HIDS patients. ${ }^{5}$ During attacks, urinary excretion of mevalonic acid increases, and measurements have diagnostic value. ${ }^{6}$

Differential diagnosis of HIDS includes familial Mediterranean fever (FMF), tumor necrosis factor receptor periodic syndrome, adult Still's disease, juvenile idiopathic arthritis, rheumatic fever, and Behçet's disease.

To our knowledge, there is no evidencebased treatment regime for HIDS. In the literature; colchicine, steroids, and non-steroidal anti-inflammatory drug treatments have been reported. Recently, positive results have been observed in randomized studies of simvastatin, anakinra, thalidomide, and etanercept. ${ }^{7,8}$ In this article, we present a HIDS case with recurring 
fever attacks who previously had a diagnosis of FMF and remained reluctant to treatment.

\section{CASE REPORT}

The patient was a 21-year-old single female. She had complaints of fever attacks, up to 39-40 degrees Celsius with chills, beginning at three years of age. She also complained of accompanying knee joint pain, nauseavomiting, abdominal pain, and diarrhea. The fever attacks lasted three days and recurred every 4-6 weeks. The patient's family history was researched, and a sibling also had joint pain and fever attacks.

Investigations during fever attacks revealed a sedimentation rate of $60 \mathrm{~mm} / \mathrm{h}$ and $\mathrm{C}$ reactive protein of $10 \mathrm{mg} / \mathrm{L}$. During the attack, the white cell count was $18,000 \mathrm{~mm}^{3}$ with sputum, urine, and blood cultures free of any microorganism. Hepatitis B surface antigen, anti-hepatitis $C$ virus, Brucella, and Salmonella were all negative. Biochemical tests were normal. Antinuclear antibody was negative; rheumatoid factor was $<20$ IU.

Genetic analysis of the patient detected K695R heterozygote mutation of Mediterranean fever gene 10 exon, FMF diagnosis was made, and colchicine treatment was begun. When the fever attacks continued in spite of colchicine treatment, the patient was evaluated for other periodic fever syndromes.
The patient had IgD (serum): $<15 \mathrm{IU} / \mathrm{mL}$ (0-100 IU/mL) and IgA (serum): $139 \mathrm{mg} / \mathrm{dL}$ (45-380 mg/dL). Genetic analysis showed homozygotic S53N mutation on MVK gene $3^{\text {rd }}$ exon, and the HIDS diagnosis was made. Our laboratory conditions were incapable of evaluating MVK enzyme activity, and mevalonic acid levels were not measured in the urine because the patient was in a non-attack period.

\section{DISCUSSION}

Hyperimmunoglobulin D syndrome develops as a result of mutations of the gene coding for the enzyme MVK, which plays a role in cholesterol and isoprenoid synthesis. ${ }^{9}$ The syndrome has an autosomal recessive trait with half of the siblings being affected. ${ }^{2}$ In our case, one sibling had a history of fever attacks but no firm diagnosis.

There are 65 different mutations found on the MVK gene. The most common mutations occurring with the disease (V377I, I268T, $\mathrm{H} 20 \mathrm{P} / \mathrm{N}, \mathrm{P} 167 \mathrm{~L})$ are responsible for $71.5 \%$ of cases. ${ }^{10}$ No relationship has been found between a certain mutation and the severity, onset of symptoms, and attack frequency in HIDS. ${ }^{11}$ HIDS patients are reported to be mostly European, especially of Dutch heritage. The most common mutation in the Dutch populations is reported to be p.V377I. ${ }^{12}$ Heterozygotic mutation of the MVK gene is found in $80 \%$ of HIDS patients. In our

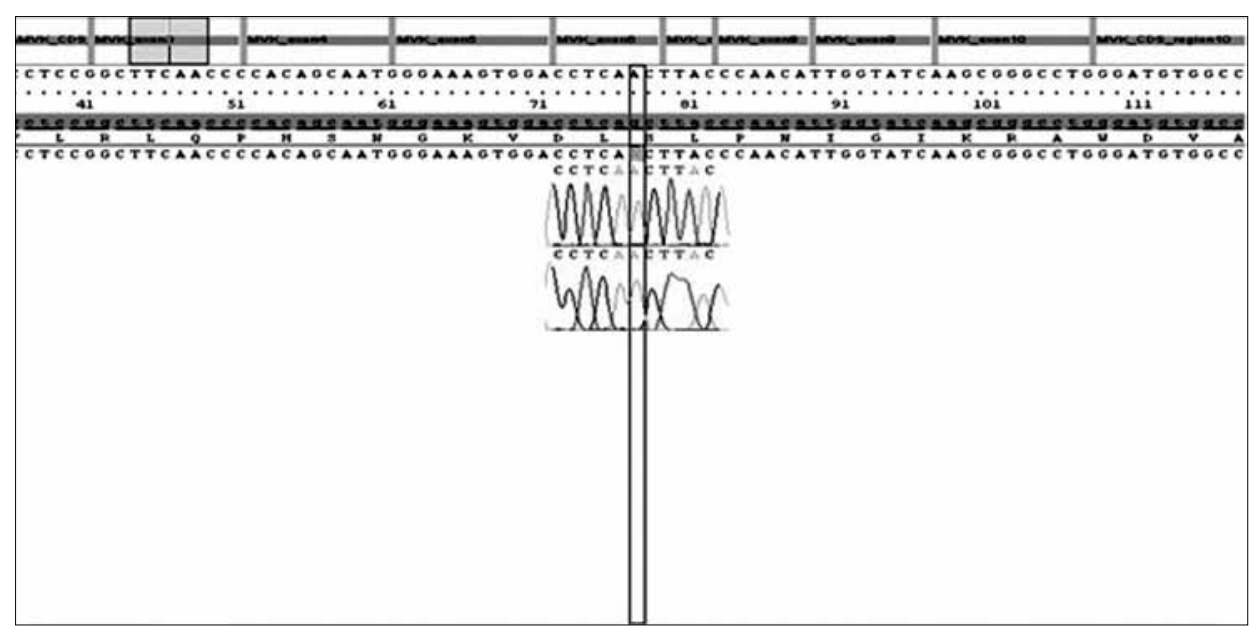

Figure 1. Mevalonate kinase gene analysis of the patient. 
case, the mutation was homozygotic S52N on the $3^{\text {rd }}$ exon of the MVK gene (Figure 1). The few cases in the literature from Turkey have G326R, V377I, I268T, T322S, M680I, R277C mutations. ${ }^{13,14}$ Some of these cases were thought to have FMF and were given colchicine. When there was no response to treatment, the HIDS diagnosis was made. ${ }^{13,15}$ Our patient was diagnosed with FMF. When fever attacks did not regress with treatment, genetic analysis was used to reach a diagnosis of HIDS.

Laboratory investigations of patients with fever attacks are helpful for differential diagnosis. Most HIDS patients have increased IgD levels although our case had normal levels of $22 \% .^{3}$ In addition, mevalonic acid in urine and serum mevalonate kinase levels can be used for firm diagnosis of HIDS.

Familial Mediterranean fever is the most frequently seen periodic fever syndrome in our country. No matter what age, cases with severe complaints that do not respond well to colchicine should be investigated for other autoinflammatory diseases. Even if serum IgD and IgA levels are normal, other periodic fever syndromes, such as HIDS, should be considered.

\section{Declaration of conflicting interests}

The authors declared no conflicts of interest with respect to the authorship and/or publication of this article.

\section{Funding}

The authors received no financial support for the research and/or authorship of this article.

\section{REFERENCES}

1. van der Meer JW, Vossen JM, Radl J, van Nieuwkoop JA, Meyer CJ, Lobatto S, et al. Hyperimmunoglobulinaemia D and periodic fever: a new syndrome. Lancet 1984;1:1087-90.

2. Drenth JP, Cuisset L, Grateau G, Vasseur C, van de Velde-Visser SD, de Jong JG, et al. Mutations in the gene encoding mevalonate kinase cause hyper-IgD and periodic fever syndrome. International Hyper-IgD Study Group. Nat Genet 1999;22:178-81.

3. Ammouri $\mathrm{W}$, Cuisset L, Rouaghe $\mathrm{S}$, Rolland $\mathrm{MO}$, Delpech M, Grateau G, et al. Diagnostic value of serum immunoglobulinaemia $D$ level in patients with a clinical suspicion of hyper IgD syndrome. Rheumatology (Oxford) 2007;46:1597-600.

4. Shendi HM, Walsh D, Edgar JD. Etanercept and anakinra can prolong febrile episodes in patients with hyperimmunoglobulin $\mathrm{D}$ and periodic fever syndrome. Rheumatol Int 2012;32:249-51.

5. Klasen IS, Göertz JH, van de Wiel GA, Weemaes CM, van der Meer JW, Drenth JP. Hyper-immunoglobulin $\mathrm{A}$ in the hyperimmunoglobulinemia $\mathrm{D}$ syndrome. Clin Diagn Lab Immunol 2001;8:58-61.

6. Bader-Meunier B, Florkin B, Sibilia J, Acquaviva C, Hachulla E, Grateau G, et al. Mevalonate kinase deficiency: a survey of 50 patients. Pediatrics 2011;128:152-9.

7. Simon A, Drewe E, van der Meer JW, Powell RJ, Kelley RI, Stalenhoef AF, et al. Simvastatin treatment for inflammatory attacks of the hyperimmunoglobulinemia $\mathrm{D}$ and periodic fever syndrome. Clin Pharmacol Ther 2004;75:476-83.

8. Drenth JP, Vonk AG, Simon A, Powell R, van der Meer JW. Limited efficacy of thalidomide in the treatment of febrile attacks of the hyper-IgD and periodic fever syndrome: a randomized, doubleblind, placebo-controlled trial. J Pharmacol Exp Ther 2001;298:1221-6.

9. Drenth JP, Haagsma CJ, van der Meer JW. Hyperimmunoglobulinemia D and periodic fever syndrome. The clinical spectrum in a series of 50 patients. International Hyper-IgD Study Group. Medicine (Baltimore) 1994;73:133-44.

10. van der Hilst JC, Bodar EJ, Barron KS, Frenkel J, Drenth JP, van der Meer JW, et al. Long-term followup, clinical features, and quality of life in a series of 103 patients with hyperimmunoglobulinemia D syndrome. Medicine (Baltimore) 2008;87:301-10.

11. van der Hilst JC, Frenkel J. Hyperimmunoglobulin D syndrome in childhood. Curr Rheumatol Rep 2010;12:101-7.

12. Lierl M. Periodic fever syndromes: a diagnostic challenge for the allergist. Allergy 2007;62:1349-58.

13. Tas DA, Dınkc1 S, Erken E. Different clinical presentation of the hyperimmunoglobulin $\mathrm{D}$ syndrome (HIDS) (four cases from Turkey). Clin Rheumatol 2012;31:889-93.

14. Gençpınar P, Makay BB, Gattorno M, Caroli F, Ünsal E. Mevalonate kinase deficiency (hyper IgD syndrome with periodic fever)--different faces with separate treatments: two cases and review of the literature. Turk J Pediatr 2012;54:641-4.

15. Topaloğlu R, Ayaz NA, Waterham HR, Yüce A, Gumruk F, Sanal O. Hyperimmunoglobulinemia $\mathrm{D}$ and periodic fever syndrome; treatment with etanercept and follow-up. Clin Rheumatol 2008;27:1317-20. 